\title{
A Case of Orthostatic Proteinuria Progressed to Persistent Proteinuria Associated with Renal Pathology
}

\author{
Yoo-Jin Kim, M.D. ${ }^{1}$ \\ Byoung-Soo Cho, M.D. ${ }^{2}$ \\ Tae Sun Ha, M.D. ${ }^{1,3}$ \\ Department of Pediatrics', Chungbuk \\ National University Hospital, Cheongju, \\ Korea, Mirae ING Hospital' ${ }^{2}$, Seoul, Korea, \\ Department of Pediatrics ${ }^{3}$, Chungbuk \\ National University College of \\ Medicine, Cheongju, Korea
}

Corresponding author: Tae Sun Ha, M.D. Department of Pediatrics, Chungbuk National University Hospital, 776 1st Sunhwan-ro, Seowon-gu, Cheongju 28644, Korea

Tel: +82-43-269-6374

Fax: +82-43-264-6620

E-mail: tsha@chungbuk.ac.kr

Received: 9 August 2017

Revised: 27 September 2017

Accepted: 1 October 2017

\footnotetext{
This is an open-access article distributed under the terms of the Creative Commons Attribution Non-Commercial License (http:// creativecommons.org/licenses/by-nc/4.0/) which permits unrestricted non-commercial use, distribution, and reproduction in any medium, provided the original work is properly cited.
}

Orthostatic or postural proteinuria is the most common cause of asymptomatic proteinuria in children. As orthostatic proteinuria (OP) is a benign disease with relatively good prognosis, it has no specific management, and patients only need to be observed. However, if OP shows a persistently high level of proteinuria, in theory, glomerular changes can occur. An 11-year-old girl was referred to the hospital due to asymptomatic proteinuria and was diagnosed as having OP based on the results of clinical and laboratory examinations, urinalysis, and protein/creatinine (TP/Cr) ratio at both supine and erect positions. During follow-up observation, the 24-hour TP/Cr ratio was persistently higher than $1.5 \mathrm{mg} / \mathrm{mg}$ for 2 years. We performed renal biopsy, which showed mesangial proliferative glomerular lesions with focal effacement of the podocyte foot processes, but without immune depositions. OP can be accompanied by glomerular lesions if moderate to severe proteinuria persists.

Key words: Proteinuria, Glomerulonephritis, Child, Orthostatic proteinuria

\section{Introduction}

Orthostatic proteinuria (OP) is a non-pathological form of isolated asymptomatic proteinuria, which is characterized by the presence of protein in urine samples collected in the upright/ambulatory position and its absence in urine samples collected in the supine position ${ }^{1,2}$. It affects $2-5 \%$ of children or young adults with asymptomatic proteinuria, but a recent report suggested a very high incidence $(\geq 15 \%)$ in children between 6 and 18 years $^{3-5)}$. In a Korean report on school health screening, OP is the most common cause $(72.1 \%)$ of asymptomatic non-transient proteinuria ${ }^{4)}$. Since OP is a benign disease with a relatively good prognosis and often resolves in adulthood, only observation is recommended, without any special treatment. Although the exact etiology is unknown, it is known to be caused by a derangement in the hemodynamic mechanisms and may be accompanied by the nutcracker phenomenon. OP can be classified into transient and stationary reproducible OP, which can lead to persistent proteinuria and cause glomerulopathy ${ }^{3,6-9)}$. This report describes a pediatric case of asymptomatic orthostatic proteinuria that progressed to persistent proteinuria with mesangial proliferative glomerular lesions. 


\section{Case report}

An 11-year-old girl was referred to our hospital for further examination because of proteinuria $2+$ found during routine school mass screening urinalysis 1 month earlier. She was well-developed and nourished, with no edema, gross hematuria, joint pain, recent notable infections, rashes, or non-steroidal anti-inflammatory drug use. Her blood pressure was $90 / 60 \mathrm{mmHg}$, and her physical examination was unremarkable. Up to now, she has not complained of any abnormal physical symptom or sign. Her serum chemical and immunologic profiles were all within normal limits, and renal ultrasound showed normal kidneys without the nutcracker phenomenon. Initial urinalysis showed specific gravity 1.026 in supine position at early morning urine and 1.013 after 2-hour upright position. And urinalysis was normal $\mathrm{pH}$ with equivocal protein $( \pm)$ in supine position and negative protein in upright position. However, her protein/creatinine ratio $(\mathrm{TP} / \mathrm{Cr})$ in supine position and upright position were 0.36 and $1.01 \mathrm{mg} / \mathrm{mg}$, respectively. Eight months later, the protein levels at supine and upright positions changed to \pm and $2+$, respectively, and the TP/Cr ratio was 0.82 and $1.9 \mathrm{mg} / \mathrm{mg}$ in supine and upright positions, respectively. In urine protein electrophoresis, albumin was a predominant fraction (61.3\%). Angiotensin II inhibitor treatment was started to reduce proteinuria. During 2 years of observation, her proteinuria was initially thought to orthostatic proteinuria; however, the TP/Cr ratio was $0.53 \mathrm{mg} / \mathrm{mg}$ in supine position and $0.4 \mathrm{mg} / \mathrm{mg}$ in upright position showed more proteinuria in the supine position. In the urinalysis, proteinuria showed $2+$ in both supine and upright positions. Angiotensin II inhibition might not have reduced her proteinuria. The maximal 24hour urine $\mathrm{TP} / \mathrm{Cr}$ ratio was 1.9 , and the maximal 24-hour urine TP was $830 \mathrm{mg}$ (Fig. 1). Laboratory tests showed normal kidney function, with blood urea nitrogen level of $10.6 \mathrm{mg} / \mathrm{dL}$ and Creatinine level of $0.4 \mathrm{mg} / \mathrm{dL}$. Although OP shows favorable prognosis, renal biopsy was performed because of persistent non-orthostatic proteinuria. Light microscopy showed moderate mesangial hypercellularity with slightly increased mesangial matrix, focal tubulointerstitial fibrosis, and atrophy without glomerulosclerosis or crescent formation. Focally marked podocyte foot process effacement was noted, and the glomerular basement membrane had normal thickness with partly irregular inner contours (Fig. 2A, B). Immunofluorescence study showed negative staining. For mesangial proliferative glomerular lesions and persistent non-orthostatic proteinuria, the patient was given low-dose steroid $(0.42 \mathrm{mg} / \mathrm{kg} /$ day $)$ and cyclosporine $(1.5 \mathrm{mg} / \mathrm{kg} /$ day) over 6 months. Currently, she is under low-dose cyclosporine and angiotensin II inhibition treatment, and her 24-hour proteinuria shows improvement, with a TP/Cr ratio $<0.3 \mathrm{mg} / \mathrm{mg}$ (Fig. 1).

\section{Kidney biopsy}

ACEi

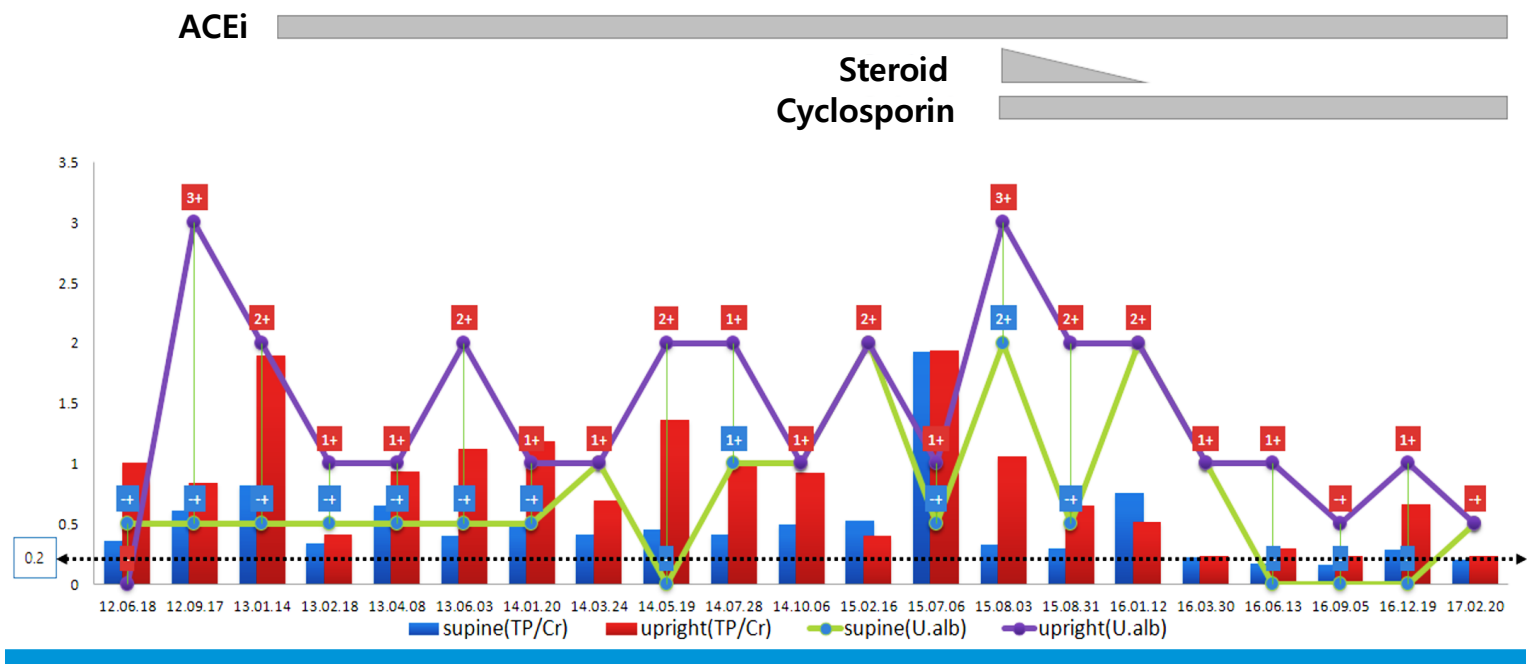

Fig. 1. Changes in the patient's day and night 24-hour urine TP/Cr ratios and urine albumin. 


\section{Discussion}

OP is a non-pathological benign condition of isolated asymptomatic proteinuria. Since OP is a benign disease with a relatively good prognosis and often resolves in adulthood, only observation is recommended, without special treatment ${ }^{1,2)}$. OP can be classified into transient and stationary reproducible forms, which can lead persistent proteinuria, and if the level of proteinuria is very high, it may cause glomerulopathy ${ }^{3,6-9)}$.

Although the exact etiology is unknown, it is known to be caused by hemodynamic mechanisms and may be accompanied with the nutcracker phenomenon. The secretion of angiotensin II and noradrenaline increases in the standing position, which affects the vascular contraction and resistance of efferent arterioles, thereby leading to proteinuria by increasing the glomerular filtration pressure and rate ${ }^{2,5)}$. Although the nutcracker phenomenon was not found in this case, it was noted in a considerable number of OP patients, which denoted that hemodynamic mechanisms might be involved in OP development ${ }^{9,10)}$. Proteinuria is also caused by or induces underlying subclinical immune injury ${ }^{11}$. As hemodynamic mechanisms, including angiotensin II and proteinuria, per se are important risk factors of renal progression ${ }^{12-14)}$, prolonged and significant proteinuria can cause glomerular and tubular changes, even though it is orthostatic. Proteinuria leads to transit of protein through glomerular structures, including the glo- merular basement membrane, the mesangium, and the podocytes, and increases traffic of protein through the proximal tubules by pinocytosis of filtered protein. This traffic of protein may injure the cells concerned, leading to glomerular and tubular injuries, such as foot process effacement, albumin deposition in podocytes, mesangial changes, and tubulointerstitial inflammation and fibrosis. Therefore, renal pathology in OP can be determined by proteinuria, a protein-overloaded condition, or an underlying subclinical glomerular injury ${ }^{12-14)}$.

Robinson et al. ${ }^{6}$ reported that evidence of a well-defined form of parenchymal renal disease was found in only $8 \%$ of 56 patients with fixed and reproducible OP, and $45 \%$ revealed distinctive glomerular alterations characterized by capillary wall thickening without basement membrane thickening, focal mesangial hypercellularity, slight capsular thickening, and the presence of eosinophilic granules within the capsular space. Thirty years later, von Bonsdorff et al. ${ }^{7)}$ reported that they found either normal or slight mesangial proliferation in light microscopy; mesangial, capillary or arteriolar deposits of complement C3 and/or immunoglobulins in 10 of $12 \mathrm{OP}$ cases in immunofluorescence study; and slight subepithelial, intramembranous, and mesangial alterations in electron microscopy; however, focal loss of the podocyte foot processes was seen in only 1 of $15 \mathrm{OP}$ cases. Therefore, they concluded that there was no histological, electron microscopic, or immunohistochemical alterations specific for OP. A rare case of OP presenting with

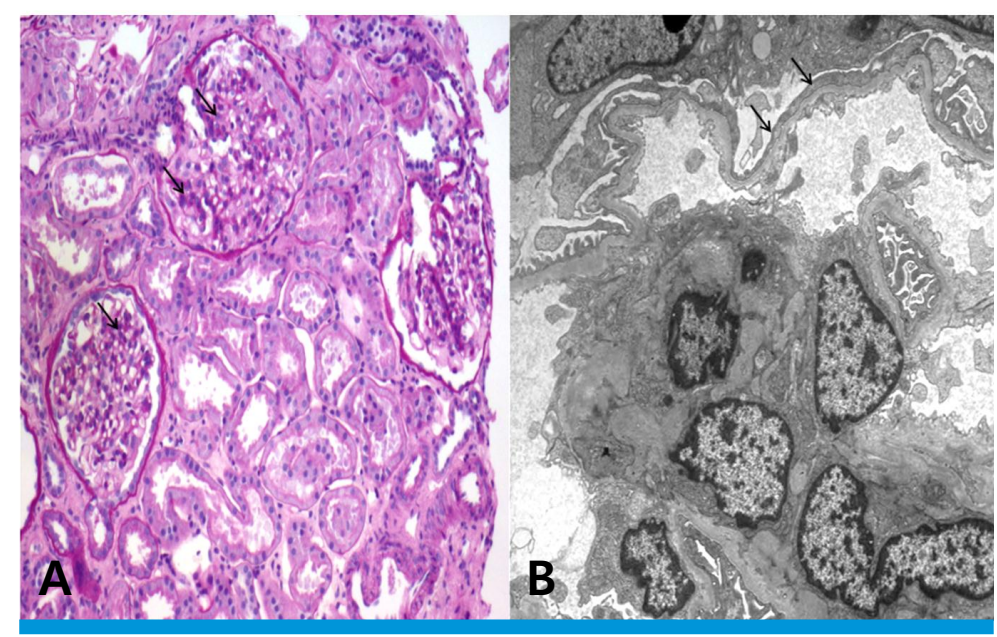

Fig. 2. Renal biopsy result. (A) Mesangial cell proliferation observed under light microscopy (Hematoxylin and eosin $\times 10$ ). (B) Focally marked podocyte foot processes effacement observed under electron microscopy $(\times 6,000)$. 
focal segmental glomerulosclerosis with nephrotic syndrome and progressive renal insufficiency developed in a 15 -year-old boy who presented initially 1 year earlier with $\mathrm{OP}^{8)}$. A case of $\mathrm{OP}$ associated with nutcracker syndrome showing mesangial hypercellularity was also reported ${ }^{9)}$. In this report, a pediatric case of asymptomatic orthostatic proteinuria that progressed to persistent proteinuria and developed mesangial hypercellularity, focal podocyte foot processes effacement, and tubulointerstitial fibrosis and atrophy. The renal pathologic lesions found in this patient may have been induced by persistent moderate to severe proteinuria due to orthostatic proteinuria or by an original glomerular pathology that presented as OP. In conclusion, children with persistent moderate to severe proteinuria should be observed closely because they can't exclude renal pathology although showing an orthostatic pattern.

\section{Conflicts of interest}

No potential conflict of interest relevant to this article was reported.

\section{References}

1. Mahan JD, Turman MA, Mentser MI. Evaluation of hematuria, proteinuria, and hypertension in adolescents. Pediatr Clin North Am 1997;44:1573-89.

2. Mazzoni MB, Kottanatu L, Simonetti GD et al. Renal vein obstruction and orthostatic proteinuria: a review. Nephrol Dial Transplant 2011;26(2):562-5.
3. Springberg PD, Garrett LE Jr, Thompson AL Jr, Collins NF, Lordon $R E$, Robinson RR. Fixed and reproducible orthostatic proteinuria: results of a 20-year follow-up study. Ann Intern Med 1982;97:516-9.

4. Park YH, Choi JY, Chung HS et al. Hematuria and proteinuria in a mass school urine screening test. Pediatr Nephrol 2005;20:112630.

5. Brandt JR, Jacobs A, Raissy HH et al. Orthostatic proteinuria and the spectrum of diurnal variability of urinary protein excretion in healthy children. Pediatr Nephrol 2010;25:1131-1137.

6. Robinson RR, Ashworth CT, Glover SM, Phillippi PF, Lecocq FR, Langelier PR. Fixed and reproducible orthostatic proteinuria. I. Light microscopic studies of the kidney. Am J Pathol 1961;39:291-301.

7. von Bonsdorff M, Törnroth T, Pasternack A. Renal biopsy findings in orthostatic proteinuria. Acta Pathol Microbiol Immunol Scand A 1982;90:11-18.

8. Berns JS, McDonald B, Gaudio KM, Siegel NJ. Progression of orthostatic proteinuria to focal and segmental glomerulosclerosis. Clin Pediatr (Phila) 1986;25:165-6.

9. Ha TS, Lee EJ. ACE inhibition can improve orthostatic proteinuria associated with nutcracker syndrome. Pediatr Nephrol 2006;21: 1765-8.

10. Shintaku N, Takahashi Y, Akaishi K, Sano A, Kuroda Y. Entrapment of left renal vein in children with orthostatic proteinuria. Pediatr Nephrol 1990;4:324-327.

11. Vehaskari VM. Mechanism of orthostatic proteinuria. Pediatr Nephrol 1990;4:328-30.

12. Remuzzi G, Bertani T. Pathophysiology of progressive nephropathies. N Engl J Med 1998;339:1448-56.

13. Erkan E. Proteinuria and progression of glomerular diseases. Pediatr Nephrol 2013; 28:1049-58.

14. Zoja C, Benigni A, Remuzzi G. Cellular responses to protein overload: key event in renal disease progression. Curr Opin Nephrol Hypertens 2004;13:31-7. 